\title{
МЕТОДИКА ЦЕНООБРАЗОВАНИЯ ОТПУСКАЕМОЙ МОЩНОСТИ ВЭС НА ОРЭМ
}

\section{(C) 2021 Сухарева Евгения Викторовна}

кандидат экономических наук, доцент кафедры Экономики в энергетике и промышленности Московский энергетический институт, Россия, Москва

E-mail: SukharevaYevV@mpei.ru

В работе проведено исследование по современному положению и перспективам развития ветроэнергетики в России и зарубежных странах. Изучен практический опыт зарубежных стран в развитии механизмов поддержки возобновляемой энергетики. Подробно рассмотрен рынок электроэнергии и мощности в РФ и проведен анализ существующих механизмов ценообразования мощности на ОРЭМ. Разработана методика определения цены отпускаемой мощности ВЭС на ОРЭМ после окончания срока ДПМ ВИЭ. Представлена апробация результатов исследования.

Ключевые слова: оптовый рынок электроэнергии и мощности, договор о предоставлении мощности, конкурентный отбор мощности, возобновляемые источники энергии, ветряная электростанция.

По мнению Российской ассоциации ветроиндустрии в РФ, в силу своего географического расположения, одним из наиболее перспективных направлений развития возобновляемых источников энергии (ВИЭ) является развитие ветроэнергетики, поэтому крайне интересным представляется опыт зарубежных стран в данном направлении [1].

В настоящее время, в России, доля ветряных электростанций неуклонно растет. Мощность данных электростанций превышает $25 \mathrm{MBT}$, что позволяет и обязывает компании, владеющие ветропарками, продавать мощность и электроэнергию на оптовом рынке электроэнергии и мощности (ОРЭМ). Вновь построенные ветростанции имеют поддержку государства в виде гарантированного возмещения затрат инвестору через повышенную стоимость продаваемой мощности (ДПМ ВИЭ) на срок 15 лет с момента ввода в эксплуатацию. Первая ветростанция, ДПМ ВИЭ которой завершится в 2031 году, является Ульяновская ВЭС -1000 «Ветропарки ФРВ» [2].

Далее возникает вопрос: «По какой цене будет продаваться мощность на ОРЭМ, отпускаемая ВЭС?» Существующие механизмы ценообразования мощности после завершения ДПМ не могут быть применены к ВЭС, так как начнется дисбаланс в системе ОРЭМ [3]. Поэтому необходимо как можно быстрее разработать новую либо усовершенствовать существующую срока ДПМ ВИЭ.

Фундаментальных работ, посвященных це- нообразованию мощности ВИЭ, практически нет $[4,5,6]$. Обусловлено это тем, что буквально недавно объекты генерации на основе ВИЭ, а именно ветряные электростанции (ВЭС) и солнечные электростанции (СЭС), вышли на оптовый рынок электрической энергии и мощности РФ, что не было до этого времени, что усложняет изучение и анализ данной темы. В настоящий момент не существует методики определения цены на мощность, отпускаемой объектами ВЭС, после окончания срока ДПМ ВИЭ.

Если принимать по аналогии ценообразование мощности объектов, которые из ДПМ перешли в конкурентный отбор мощности (КОМ) [7], то объекты ВИЭ (ВЭС и СЭС) будут иметь завышенную прибыль. Причина в том, что условно постоянные затраты (УПЗ), а именно заработная плата, ремонты оборудования, амортизация, транспортные затраты, канцелярия и др. для объектов ВИЭ являются минимальными по сравнению с УПЗ теплоэлектроцентрали (ТЭЦ). С каждым годом доля ВИЭ и объемы мощности на оптовом рынке электроэнергии и мощности будут неуклонно расти, следовательно, влияние на формирование цены на ОРЭМ окажется значительным. Цена мощности на ОРЭМ начнет падать. При подаче ценовых заявок отбираются генерирующие объекты с наиболее низкой ценой, значит, объекты ВИЭ начнут вытеснять объекты многих тепловых станций по причине того, что эти самые ТЭЦ не смогут предложить такую цену, которая покрывала бы их условно постоянные издержки. Объекты традиционной 

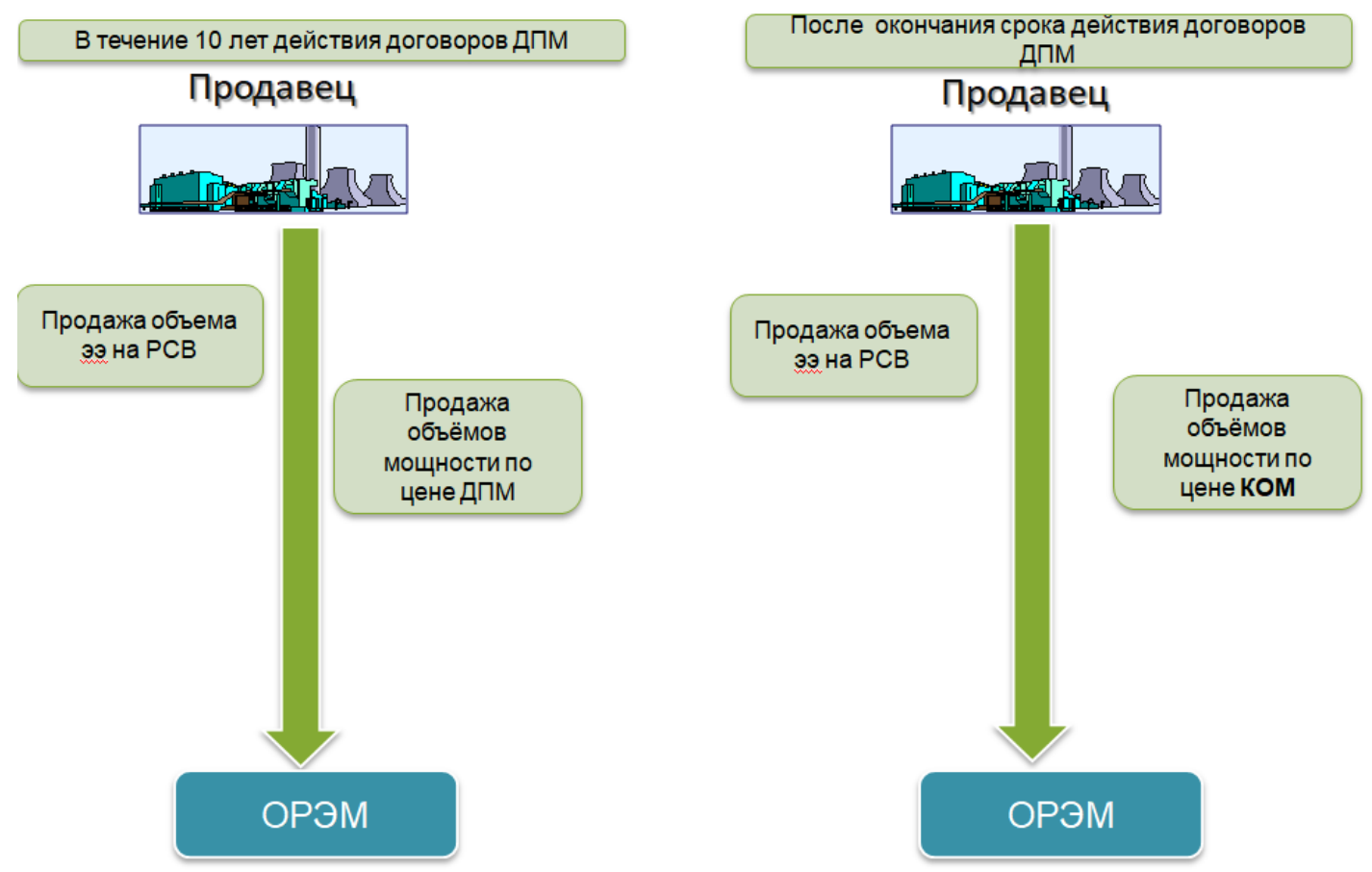

Puc. 1. Действующий механизм продажи электроэнергии и мощности

энергетики попросту не смогут конкурировать со станциями ВИЭ, становясь нерентабельными для выработки мощности. Таким образом, модель КОМ, представленная на рисунке 1, нецелесообразна для применения ее к объектам ВЭС на ОРЭМ [8]. Аналогичная ситуация и с другими секторами ОРЭМ.

Что касается такого механизма ценообразования мощности на ОРЭМ как вынужденный режим, то данный механизм тоже не применим к ВЭС. Он направлен на объекты генерации, не прошедшие конкурентный отбор мощности на рынке, так как они являются нерентабельными, неэффективными, морально устаревшими, имеют высокие удельные затраты, что не относится к объектам ВИЭ, в частности ВЭС.

В таблице 1 сведены действующие механизмы ценообразования мощности на ОРЭМ и при-

\section{Таблица 1. Сравнение механизмов ценообразования на ОРЭМ [9]}

\begin{tabular}{|c|c|}
\hline Механизмы ОРЭМ & Причины \\
\hline $\begin{array}{c}\text { Конкурентный отбор } \\
\text { мощности (КОМ) }\end{array}$ & $\begin{array}{l}\text { 1) В КОМ ценовые заявки генерирующих компаний сравниваются и отбираются } \\
\text { с наиболее низкими условно-постоянными затратами. УПЗ объектов ВЭС намного } \\
\text { ниже, чем условно-постоянные затраты ТЭЦ, значит и цена на мощность будет } \\
\text { ниже, чем цена КОМ. Цена КОМ одинакова для всех отобранных объектов; } \\
\text { 2) При установлении цены КОМ объектам ВИЭ произойдёт дисбаланс на ОРЭМ, так } \\
\text { как объекты ВЭС начнут вытеснять объекты традиционной энергетики с ростом } \\
\text { объёмов вводов. }\end{array}$ \\
\hline $\begin{array}{l}\text { Свободные договоры } \\
\text { купли - продажи мощ- } \\
\text { ности (СДМ) }\end{array}$ & $\begin{array}{l}\text { 1) Цена СДМ формируется на уровне цены на КОМ; } \\
\text { 2) Заключаются прямые договоры с потребителями, путём снижения объёмов про- } \\
\text { даж с КОМ для целей избегания неплатежей проблемными контрагентами; } \\
\text { 3) Для объектов ВИЭ ценообразование по СДМ неприемлем, так как не учитывает } \\
\text { продажу-покупку э/э на РСВ и БР. }\end{array}$ \\
\hline $\begin{array}{c}\text { Вынужденный режим } \\
\text { (ВР) }\end{array}$ & $\begin{array}{l}\text { 1) Применяется к объектам генерации, не прошедшие КОМ по причине нерента- } \\
\text { бельности, морального износа оборудования, высоких удельных затрат на произ- } \\
\text { водство э/э, мощности и тепловой энергии. }\end{array}$ \\
\hline $\begin{array}{c}\text { Регулируемые догово- } \\
\text { ры (РД) }\end{array}$ & $\begin{array}{l}\text { 1) Установление двухставочного тарифа ФАС России. Устанавливается как тариф на } \\
\text { электроэнергию, так и тариф на мощность; } \\
\text { 2) Применяется для объёмов, которые поставляются населению и предприятиям } \\
\text { Кавказского региона. }\end{array}$ \\
\hline
\end{tabular}



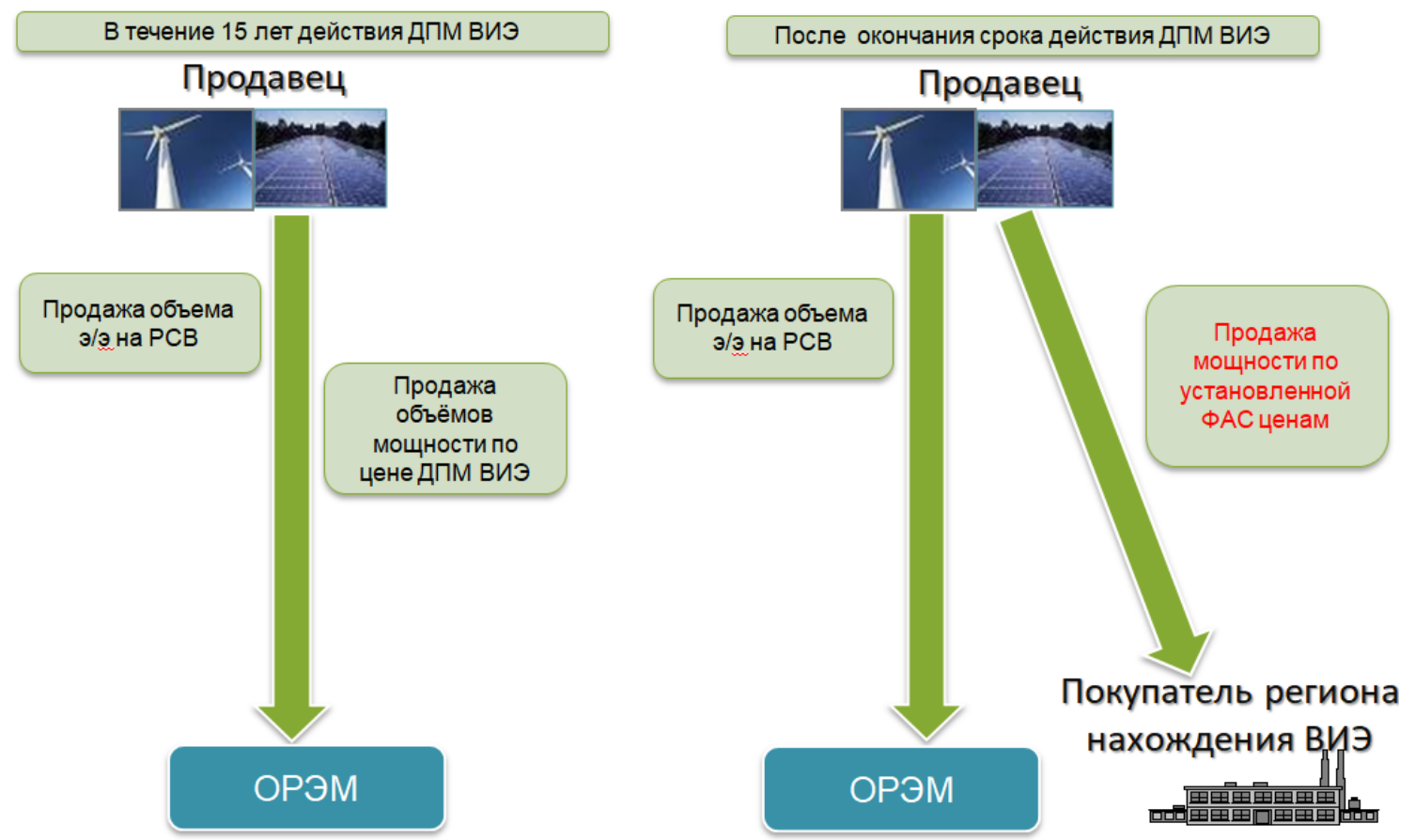

Puc. 2. Предлагаемая схема продажи электроэнергии и мощности после окончания срока ДПМ ВИЭ

чины, по которым невозможно их использование для объектов ВЭС после окончания срока ДПМ ВИЭ.

Предлагается, после окончания срока ДПМ ВИЭ, осуществлять продажу мощности непосредственно региону, где расположены ветропарки, а электрическую энергию - на ОРЭМ (схема представлена на рисунке 2).

Данная схема имеет ряд преимуществ:

1) Цена на мощность будет ниже, чем цена КОМ, следовательно, ниже цена энергоносителя для конечного потребителя, так как произойдет замещение части покупаемой мощности на ОРЭМ объемом мощности ветропарков;

2) Привлекательность расположения объектов ВИЭ для Губернаторов регионов в целях снижения себестоимости энергоносителей для развития производства [10];

3) Схема может применяться для любых регионов РФ, где располагаются объекты ВИЭ, в частности ветряные (ВЭС) и солнечные элек- тростанции (СЭС), срок ДПМ, которых близится к завершению;

4) Отсутствие дисбаланса на ОРЭМ. Объекты ВЭС не повлияют отрицательно на ценообразование отпускаемой мощности других энергетических объектов на ОРЭМ.

Для определения цены на мощность ветряных электростанций предлагается установить тариф. Расчет данного тарифа на мощность ВЭС производится по формуле:

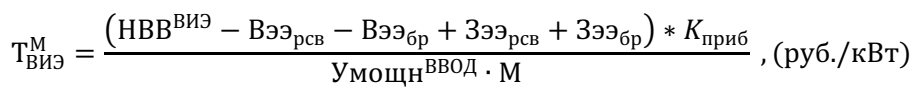

где

$\mathrm{HBB}^{\text {виэ }}$ - необходимая валовая выручка на производство мощности квалифицированного генерирующего объекта ВИЭ (тыс. руб.);

$\mathrm{y}_{\text {мощн }}$ ввод - установленная мощность квалифицированного генерирующего объекта ВИЭ (кВт);

М - количество месяцев.

Вээ $_{\text {рсв }}$ - планируемые на і-й расчетный пе-

Таблица 2. Сравнение технико-экономических показателей

\begin{tabular}{|l|c|c|}
\hline \multicolumn{1}{|c|}{ Показатель } & КОМ & Предлагаемая методика \\
\hline Цена, руб./МВт/мес. & 307489 & 2122017 \\
\hline Выручка по э/э и мощности, млн. руб. & 294,6 \\
\hline $\begin{array}{l}\text { Прибыль до вычета амортизации и налогов, млн. } \\
\text { руб. }\end{array}$ & 83,1 & 6,57 \\
\hline Прибыль до вычета налогов, млн. руб. & 83,1 & 6,57 \\
\hline Чистая прибыль, млн. руб. & 66,5 & 5,26 \\
\hline Рентабельность, & 23 & 2 \\
\hline
\end{tabular}


риод регулирования выручка за проданную электрическую энергию на РСВ, тыс. руб.;

Вээ од регулирования выручка за проданную электрическую энергию на БР, тыс. руб.;

$3 э_{\text {рсв }}$ - планируемые на і-й расчетный период регулирования затраты на покупку электрической энергии на РСВ для собственных нужд, тыс. руб.;

Зээ риод регулирования затраты на покупку электрической энергии на БР в обеспечении баланса, тыс. руб.;

$\mathrm{K}_{\text {приб }}$ - установленный коэффициент прибыли (устанавливает ФАС).

$$
\mathrm{HBB}_{i}=P_{1, i}+P_{2, i}+H_{i} \pm \Delta \mathrm{HBB}_{i} \text {, (тыс. руб. ) }
$$

где

$\mathrm{P}_{1, \mathrm{i}}$ - планируемые на i-й расчетный период регулирования расходы, уменьшающие налоговую базу налога на прибыль организаций (расходы, связанные с производством и реализацией продукции (услуг), и внереализационные расходы), тыс. руб.;

$\mathrm{P}_{2, \mathrm{i}}$ - планируемые на i-й расчетный период регулирования расходы, не учитываемые при определении налоговой базы налога на прибыль (расходы, относимые на прибыль после налогообложения), тыс. руб.;

$\mathrm{H}_{\mathrm{i}}$ - планируемая на i-й расчетный период регулирования величина налога на прибыль, определяемая в соответствии с Налоговым кодексом Российской Федерации (часть вторая) тыс. руб.;

$\Delta \mathrm{HBB}_{\mathrm{i}},-$ величина, учитывающая экономи- чески обоснованные расходы производителя (выпадающие доходы), а также выручку и покупку э/э на РСВ и БР, подлежащие возмещению (со знаком «+») в і-м расчетном периоде регулирования, необоснованные расходы, подлежащие исключению из НВВ (со знаком «-») в і-м расчетном периоде регулирования.

Произведена апробация предложенной методики на примере Ульяновской ВЭС - 1 ООО «Ветропарки» ФРВ [11]. Произведен расчет основных технико-экономических показателей Ульяновской ВЭС - 1 при действующей цене возврата инвестиций ДПМ ВИЭ:

- Цена на мощность = 2486619,33 руб./МВт/ мес.;

- Выручка по электроэнергии и мощности = 1121,9 млн. руб.;

- Валовая прибыль = 1117,770 млн. руб.;

- Смета условно-постоянных затрат = 163,612 млн. руб.;

- Прибыль до вычета амортизации и налогов = 954,158 млн. руб.;

- Прибыль до вычета налогов = 605,200 млн. руб.;

- Чистая прибыль = 483,0 млн. руб.;

- Рентабельность ветростанции = 43\%;

Произведен расчет предлагаемой цены на мощность ВЭС и основных техникоэкономических показателей в сравнении с механизмом ценообразования мощности КОМ, который применяется для генерирующих объектов, срок ДПМ которых подошел к концу (таблица 2).

В результате расчетов и построенного графика (рисунок 3) мы видим, что предлагаемая цена на мощность ВЭС после окончания срока ДПМ ВИЭ значительно ниже цены КОМ, что эко-

Сравнительная динамика цен на мощность ВИЭ
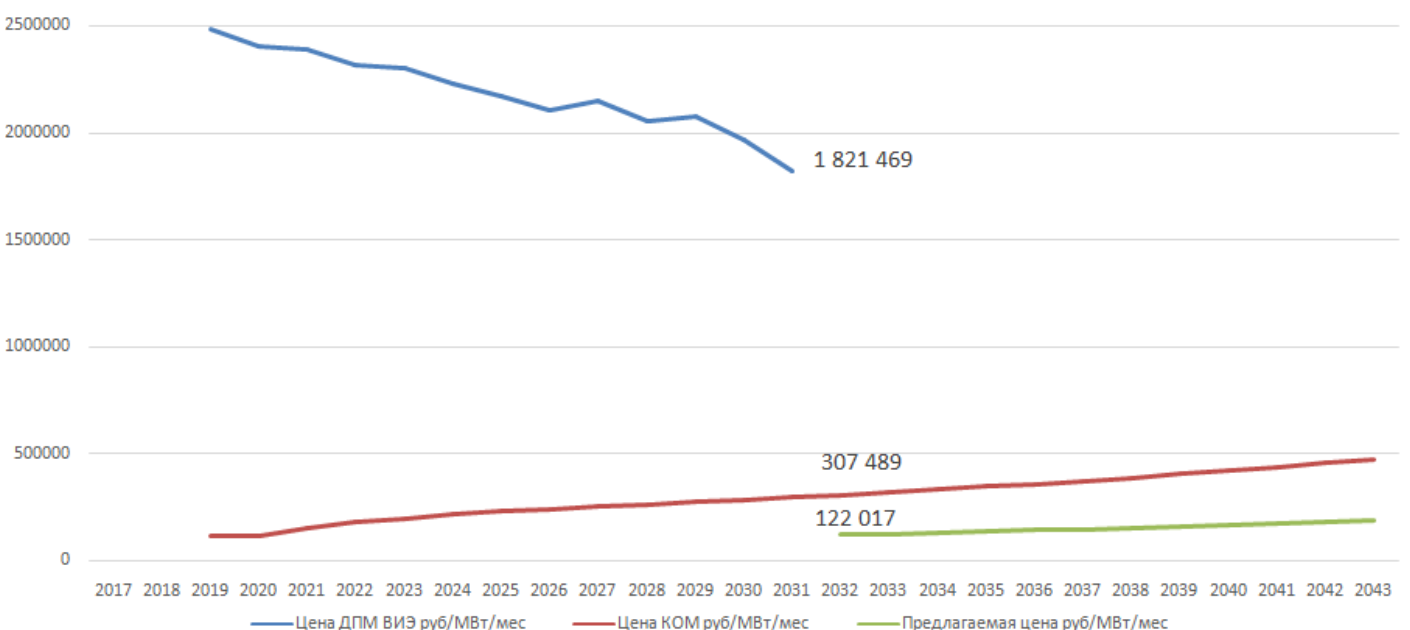

Puc. 3. Сравнительная динамика цен на мощность ВИЭ 
номически выгодно для Ульяновской области. Произойдет замещение части покупаемой мощности на ОРЭМ объемом ветропарков и снижение средневзвешенной цены на мощность для потребителей региона.

Сравнивая показатели, видно, что цена на мощность согласно разработанной методике практически в 3 раза меньше цены существующего механизма KOM, но и техникоэкономические показатели меньше и находятся в адекватном диапазоне.

Учитывая выше сказанное, можно сделать вывод, что предлагаемая методика, экономически выгодна в первую очередь для регионов, где расположены ветропарки, так как цена на мощность будет ниже, чем цена КOM, следовательно, ниже цена энергоносителя для конечного потребителя, так как произойдет замещение части покупаемой мощности на ОРЭМ объемом мощности ветропарков, а также произойдет снижения себестоимости энергоносителей, что положительно скажется на развитии производства региона.

\section{Библиографический список}

1. Электронный портал www.gisee.ru [Электронный ресурс] / «Мировой опыт в освоении энергии ветра», https://gisee.ru/articles/foreign_stat/20153/

2. Электронный портал www.fortum.ru [Электронный ресурс] / «Ветряная электрическая станция в Ульяновской области». Режим доступа: https://www.fortum.ru/vetryanaya-elektricheskaya-stanciya-v-ulyanovskoyoblasti

3. Миролюбова, Е. Ветроэнергетика в России: состояние, тенденции, перспективы / Е. Миролюбова, М. Карнаухова // Электроэнергия. Передача и распределение. - 2013. - № 2. - С. 116-119

4. Николаев, В.Г. Состояние и перспективы развития мировой и отечественной ветроэнергетики / В.Г. Николаев, С. В.Ганаг, Э. М. Перминов // Библиотечка электротехника. - 2012. - № 8. - С. 1-124.

5. Федорова, E. Механизмы поддержки возобновляемых источников энергии в России / Е. Федорова // Энергорынок. - 2019. - № 16. - С. 56-57.

6. Иванникова, Е. М., Возобновляемые источники энергии в Российской Федерации и поддержка государства. Альтернатив. энерг. и экол.. / Е. М. Иванникова, В. Г. Систер, А. П. Василенко, Е. С. Кольцова, Ю. М. Иванникова. - 2015, N 17-18, с. 172-175.

7. Постановление Правительства РФ от 29.12.2011 № 1178 (ред. от 17.08.2020) «О ценообразовании в области регулируемых цен (тарифов) в электроэнергетике»

8. Постановление Правительства РФ от 31 августа 2006 г. N 529 «О совершенствовании порядка функционирования оптового рынка электрической энергии (мощности)» (с изменениями и дополнениями).

9. Электронный портал www.base.garant.ru [Электронный ресурс] / «Методические указания по расчету тарифов на электрическую энергию и мощность по договорам купли-продажи по регулируемым тарифам (ценам) на оптовом рынке». Режим доступа: https://base.garant.ru/190088/53f89421bbdaf741eb2d1ecc4ddb4c 33/\#friends

10. Белей В. Ф. Возобновляемые источники энергии - энергия будущего. Инновации в науке, образовании бизнесе - 2014: 12 Международная научная конференция, Калининград, 15-17 окт., 2014: Труды. Ч. 1. Калининград. 2014, с. 316-319.

11. Электронный портал www.mcwindenergy.com [Электронный ресурс] / «Проекты ООО «Ветропарки ФРВ». Режим доступа: https://mcwindenergy.com/catalog/2 